\title{
Analysis of caesarean-section rates according to Robson's ten group classification system and evaluating the indications within the groups
}

\author{
Amita Ray*, Sumy Jose
}

Department of Obstetrics and Gynecology, DM Wayanad Institute of Medical Sciences, Wayanad, Kerala, India

Received: 03 January 2017

Accepted: 11 January 2017

\section{*Correspondence:}

Dr. Amita Ray,

E-mail: amitarays@gmail.com

Copyright: ( ) the author(s), publisher and licensee Medip Academy. This is an open-access article distributed under the terms of the Creative Commons Attribution Non-Commercial License, which permits unrestricted non-commercial use, distribution, and reproduction in any medium, provided the original work is properly cited.

\section{ABSTRACT}

Background: With Caesarean sections on the rise WHO proposes that health care facilities use the Robson's 10 group classification system to audit their C-sections rates. This classification would help understand the internal structure of the CS rates at individual health facilities identify key population groups, indications in each group and formulate strategies to reduce these rates.

Methods: This was a cross sectional study for a period of 24 months at a tertiary care hospital in a tribal area of Kerala South India. Women who delivered during this period were included and classified into 10 Robson's classes and percentages were calculated for the overall rate, the representation of groups, contribution of groups and Caesarean percentage in each group.

Results: Highest contribution was by Group 5 and Group 2. Together these two groups contributed to $38 \%$ of the total Caesareans. Followed by Group 8 and 10. All four added contributed to $63 \%$ of the section rate The least contribution was by Group 3. Groups 6, 7 and 9 by themselves did not contribute much but within their groups had a $100 \%$ C-Section rate.

Conclusions: The contribution of the various Robson's Group to the absolute C-Section rates needs to be looked into. Reducing primary section rates, adequate counselling and encouraging for VBAC, changing the norms for dystocia and non-reassuring fetal status, training and encouraging obstetricians to perform versions when not contraindicated could reduce the contribution of Robson's groups towards the absolute C-Section rates.

Keywords: C-section, HDI, Robson's classification

\section{INTRODUCTION}

It is a well-established that caesarean section (CS) rates have risen in both developed and developing world over the past three decades. ${ }^{1-3}$ Developed countries like the Unites States have seen a drastic rise in C-Sections from 1996 to-2011. ${ }^{4}$ The developing world too has seen a similar rise. Countries in south east Asia and sub Saharan Africa have recorded increases in C-Section rates though they vary widely from one country to the other. ${ }^{5,6}$ In India the average C-Section rate till 2006 stands at $8 \%$ as per the World Health Organization (WHO). This is an increase over the rates recorded in 1992 (2.4\%) and subsequently $1996(6.8 \%){ }^{7}$ But this national rate of $8 \%$ can well mask the differences within the country and national data after 2006 is not available India has substantial variations in the availability, quality and acceptability of health care facilities including maternal health. Tertiary care centres have high $\mathrm{C}$-Section rates but areas where health care facilities are not available may have maternal deaths due to lack of C-Section facilities. ${ }^{8-10}$

It would therefore be prudent to assess caesarean section rates in tertiary health care facilities which could in some ways be representative of the $\mathrm{C}$-section rates of the population which is catered to by that centre.

Also each of these centres as proposed by WHO should use the Robson's 10 group classification system to audit 
their C-Sections rates. This classification would help understand the internal structure of these rates at individual health facilities and specific population groups. ${ }^{11-13}$

Identifying the indications that lead to each group's contribution to the section rates would help in formulating guidelines to reduce rates. Within groups without compromising maternal and fetal welfare In 2015, the WHO issued an official statement concerning CS rates and promoting the use of the Robson classification as a tool for optimizing the CS rate at health care facilities. ${ }^{14}$ With this in mind we framed the following objectives for our study

\section{Aims and objectives}

- To classify our population into the 10 Robson's groups

- To identify which among these groups have the highest C-Section rates

- To formulate plans of reducing these rates

\section{METHODS}

Approval was obtained fronm the Institutional Review Board (IRB).This was a cross sectional study was conducted for a period of 24 months from December 2014 to November 2016 at DM Wayanad Institute of Medical Sciences, a tertiary care hospital in a tribal area of the state of Kerala in South India. All the women delivered during this period whether booked or unbooked were included. All relevant information (see below) which would help to classify the women according to the Robson's 10 classes were entered into an excel chart on a monthly basis Results were calculated at the end of 24 months.

Percentages were calculated for the overall rate, the representation of the group's contribution of each group to the overall rate and percentage in each group.

There are two classifications one is the original Robson's and the other is its modified version.

We used the original Robson's classification which goes as follows:

1. Nulliparous, single cephalic, $>37$ wks in spontaneous labor.

2. Nulliparous, single cephalic, $>37$ wks, induced or CS before labor.

3. Multiparous (excluding previous CS), single cephalic, $>37$ weeks in spontaneous labor.

4. Multiparous (excluding previous CS), single cephalic, $>37$ weeks, induced or CS before labor.

5. Previous CS, single cephalic, $>37$ weeks.

6. All nulliparous breeches.

7. All multiparous breeches (including previous CS).

8. All multiple pregnancies (including previous CS).

9. All abnormal lies (including previous CS).

10. All single cephalic, <36 wks (including previous CS).

\section{RESULTS}

The total number of women who delivered were 1624 . There were 1640 live births as 16 were twins. The total numbers of C-Sections were 474 and the overall CSection rate for this period of time at our hospital was 28.90 (Table 1).

Table 1: Description of the Robson's groups in our population.

\begin{tabular}{|lllll|}
\hline Robson's group & Total no in group & $\begin{array}{l}\text { Relative } \\
\text { sive }(\%)\end{array}$ & C-Section rate (\%) & $\begin{array}{l}\text { CS/ all live } \\
\text { births } \%\end{array}$ \\
\hline 1 & 360 & 22.16 & $6.94(25$ sections $)$ & 1.52 \\
\hline 2 & 180 & 11.08 & $45(81$ sections $)$ & 4.93 \\
\hline 3 & 620 & 38.17 & $1.93(12$ sections & 0.73 \\
\hline 4 & 80 & 4.92 & $27.5(22$ sections $)$ & 1.34 \\
\hline 5 & 160 & 9.85 & $85(136$ sections $)$ & 8.29 \\
\hline 6 & 40 & 2.46 & $100(40$ sections $)$ & 2.43 \\
\hline 7 & 1.23 & $100(20)$ & 1.21 \\
\hline & 20 & & $54.58(62)$ & 3.78 \\
\hline 9 & 120 & 7.38 & 62 sections lead to 78 live births & \\
\hline 10 & Live births are $120+16=136$ & so rate is 62 divided by 136 & 1.21 \\
\hline Total & $(16$ twin deliveries) & 1.23 & $100(20)$ & 3.41 \\
\hline
\end{tabular}


We calculated CS rates separately for booked and unbooked cases.

Booked cases were defined as having had three antenatal check-ups with us as defined by the Ministry of Health and Family Welfare of India guidelines. ${ }^{15}$ The C-Section rate for un-booked cases was $36.3 \%$ (227 sections out of 624 live births) and that of booked cases was $24.3 \%$ (247 out of 1016 live births) (Table 2).

Table 2: Section rates in booked and un-booked cases.

\begin{tabular}{|llll|}
\hline & $\begin{array}{l}\text { Total number } \\
\text { of live births }\end{array}$ & $\begin{array}{l}\text { C- } \\
\text { sections }\end{array}$ & Percentage \\
\hline $\begin{array}{l}\text { Booked } \\
\text { cases }\end{array}$ & 1016 & 247 & 24.3 \\
\hline $\begin{array}{l}\text { Unbooked } \\
\text { cases - }\end{array}$ & 624 & 227 & 36.3 \\
\hline
\end{tabular}

Robson's Group 3 had the greatest representation in our population followed by Group 1 and 2. Groups 7 and 9 had the least representation (Table 1).

Contribution to the total section rates was highest by Group 5 followed by Group 2. Together these two groups contributed to $38 \%$ of the total Cesareans Then came group 8 and 10 . When all four groups were added they contributed to $63 \%$ of the section rate. The least contribution was by Group 3 (Table 1).

Percentage wise groups 6,7 and 9 had the greatest section rates all had $100 \%$ section rates meaning all women in these three groups underwent CS. Followed by group 5 and 8 which had $85 \%$ and $54 \%$ respectively (Table 1).

\section{DISCUSSION}

\section{Overall section rates}

Our overall C-Section is $29.8 \%$. WHO proposes that at a population level caesarean section rates higher than $10 \%$ are not associated with reductions in maternal and newborn mortality rates. Our higher rates reflect the hospital section rate and not the population section rate. Ours is the biggest referral centre in the Wayanad District and receives several referrals from centres not well equipped. To be truly representative of the population section rate we have to include the live births in all other hospitals in this district When compared to other countries our rates were lower than those of the USA $(31.1 \%)$ and Australia (30\%), higher than that of Norway $(13.9 \%)$ and almost same as that of the Asian countries $(27.3 \%) .{ }^{16-20}$ However our rates should not be equated with the national rate as recent data about Indian CSection rates are not available.

Section rates for un-booked cases were higher than the booked cases which could be explained by last minute referrals, unavailability of section and transfusion facilities at the primary booking centre or other logistics.

For further comparisons we have used a study published in the Lancet in 2012. ${ }^{21}$ This study has reported deliveries in 287 facilities in 21 countries that were included in both the WHO Global Survey of Maternal and Perinatal Health (WHOGS; 2004-08) and the WHO Multi-Country Survey of Maternal and Newborn Health (WHOMCS; 2010-11). Using this data countries were stratified according to Human Development Index (HDI) groups (very high/high, medium, or low) and the Robson criteria were applied to both datasets. The relative size of each Robson group, the caesarean section rate in each Robson group, and the absolute and relative contributions made by each to the overall caesarean section rate was reported.

\section{Representation of the Robson's groups}

In our population Group 3 had the greatest representation followed by Groups 1 and 2. We compared this representation with other countries categorized based on Human Development Index which also showed the same trend. India is categorised under Medium HDI.

Group 5 has the greatest absolute contribution to the CSection rates in our study and this was echoed in the Lancet article where all three HDI category countries were compared and group 5 was found to have the largest contribution. .However the next greatest contribution to the absolute $\mathrm{C}$-section rate was by Group 2 in our study whereas the Lancet study uniformly finds the group 1 to be the next greatest contributor irrespective of the HDI status of the country.

\section{Analysis of the indications for C-section in these two groups}

In Group 5 out of 160 in this group 136 underwent CSection. 102 women were fit for and were offered VBAC 33 accepted and rest chose elective section without going into labor. On asking the reason we got answers as "afraid prior stitches might open up", "one has been done so why not two", "can do ligation simultaneously". It appears that with this group counselling and preparedness for VBAC may be the means to decrease section rates. Of the ones that agreed for $\mathrm{VBAC}$ non progress and nonreassuring fetal status were the chief indications for section.

In Group 2 again the chief indications for C-Section were non progress and non-reassuring fetal status.

It would be therefore be prudent to address these two most important indications contributing to high C-Section rates in both these groups In this context it would be good to follow the guidelines (March 2014) developed jointly by the American college of Obstetrics and Gynaecologists and the Society for Foetal and Maternal Medicine for safe reduction of caesarean section rates. ${ }^{22}$ 


\section{Remedial measures suggested reducing rates}

\section{For dystocia}

a) Consider the threshold of $6 \mathrm{~cm}$ (not $4 \mathrm{~cm}$ as earlier) dilatation as the beginning of the active phase.

b) Latent phase could be prolonged beyond 20 hours in primi-para (earlier 12) and 14 hours (earlier 8) in a multi-para.

c) Consider arrest only if no progress after 4 hours of adequate uterine contractions or 6 hrs with oxytocin infusion.

d) Do not apply rules of progress of labour before $6 \mathrm{~cm}$ dilatation.

e) In second stage Allow for pushing for two hours in multipara and three hours in primipara.

f) Rotate occiput manually.

g) Try instrumental delivery.

\section{For non-reassuring foetal status}

a) Improve the documentation of the non-reassuring status.

b) Categorize foetal heart rate tracing whereby Category I is normal, Category III which is ominous requiring immediate delivery and the rest as Category II. -For Category II try, as well as.

c) Document resuscitative measure like maternal repositioning, oxygen supplementation and scalp stimulation to illicit acceleration.

Group 1 in our study had a considerably lesser contribution to the absolute C-Section rates which is of great importance in reducing primary section rates and should be maintained or even improved.

Groups 6, 7 and 9 had lesser representation but a 100\% $\mathrm{C}$-Section rates .These three groups mainly represented the mal presentations and this part could have been reduced by versions. Both primi and multi particularly those with un-scarred uterus could undergo versions and stabilizing inductions. Also breech delivery in multis could be promoted.

\section{CONCLUSION}

Even though the overall CS rate in the study is not high as compared to international studies, the contribution of the various Robson's Group to the absolute C-Section rates needs to be looked into. Reducing primary section rates, adequate counselling and encouraging for $\mathrm{VBAC}$, changing the norms for dystocia and non-reassuring fetal status, training and encouraging obstetricians to perform versions when not contraindicated could reduce the contribution of Robson's groups towards the absolute CSection rates. More studies using this classification could further help obstetricians and hospitals formulate strategies to reduce their section rates till they reach the proposed WHO recommendations.

\section{ACKNOWLEDGEMENTS}

We are grateful to all our labor room sisters who helped us collect the data and feed it into excel sheets. We are grateful to our institutional statistician Mr. Arun Gopi who helped us tabulate the data as per the Robson's groups and calculate the percentages.

Funding: No funding sources

Conflict of interest: None declared

Ethical approval: The study was approved by the Institutional Review Board (IRB)

\section{REFERENCES}

1. Betram AP, Merialdi M, Lauer JA, Bing-Shun W, Thomas J, Van Look P, et al. Rates of caesarean section: analysis of global, regional and national estimates. Paediatr Perinat Epidemiol. 2007;21:98-113.

2. Zizza A, Tinelli A, Malvasi A, Barbone E, Stark M, De Donno A, et al. Caesarean section in the world: a new ecological approach. J Prev Med Hyg. 2011;52:161-73.

3. Litorp H, Kidanto H, Nystrom L, Darj E, Esse'n B. Increasing caesarean section rates among low-risk groups: a panel study classifying deliveries according to Robson at a university hospital in Tanzania. BMC Pregnancy Childbirth. 2013;13:107.

4. Martin JA, Hamilton BE, Ventura SJ, Osterman MJ, Mathews TJ. Births: Final data for 2011. Natl Vital Stat Rep. 2013:62:1-90.

5. Stanton CK, Holtz SA. Levels and trends in cesarean birth in the developing world. Stud Fam Plann. 2006;37:41-8.

6. Ribeiro V, Figueiredo F, Silva A, Bettiol H, Batista R, Coimbra L, et al. Why are the rates of cesarian section in Brazil higher in more developed cities than in less developed ones? Brazilian Journal of Medical and Biological Research. 2007;40:1211-20.

7. Cavallaro FL, Cresswell JA, França GVA, Victora CG, Barros AJD, Ronsmans C. Trends in caesarean delivery by country and wealth quintile: cross-sectional surveys in southern Asia and sub Saharan Africa. Bulletin of World Health Organization published on line on August 2013. Obtained from http://www.who.int/bulletin/volumes/91/12/13117598/en/ accessed on August 2014.

8. Horton R, Das P. Indian health: The path from crisis to progress the Lancet. 2011;377:181-3.

9. Kapil U, Choudhury P. National Rural Health Mission (NRHM): Will it make a Difference? Indian Pediatrics; 2005;42:783.

10. Ray A, Vadvagi N. Assessment and comparison of Caesarean section rates to WHO recommendations Authors. The Online Journal of Clinical Audits. 2015;7(4):1-8.

11. Robson M. Classification of caesarean sections. Fetal Matern Med Rev 2001;12:23-39.

12. Robson M. Can we reduce the caesarean section rate? Best Pract Res Clin Obstet Gynaecol. 2001;15:179-94.

13. Torloni MR, Betran AP, Souza JP, Widmer M, Allen T, Gulmezoglu M, et al. Classifications for cesarean 
section: a systematic review. PLoS ONE. 2011;6:e14566

14. Hartmann K, Andrews J, Jerome R, Lewis R, Likis F, McKoy J, et al. Strategies to reduce cesarean birth in low-risk women. Agency Healthcare Res Qual (US) Rep. No. 2012;12(13)-EHC128-EF.

15. Guidelines for antenatal care at birth -National Health Portal

http://www.nhp.gov.in/sites/default/files/anm_guideline s.pdf accessed on September 2014

16. MacDorman MF, Menacker F, Declercq E. Cesarean birth in the United States: epidemiology, trends, and outcomes. Clin Perinatol. 2008 Jun;35(2):293-307.

17. Stavrou EP, Ford JB, Shand AW, Morris JM, Roberts CL. Epidemiology and trends for Caesarean section births in New South Wales, Australia: a populationbased study. BMC Pregnancy Childbirth. 2011;11:8.

18. Laws PJ, Sullivan EA. Australia's mothers and babies. Sydney 2007;2009.

19. Kolås T, Hofoss D, Daltveit AK, Nilsen ST, Henriksen $\mathrm{T}$, Häger R, et al. Indications for cesarean deliveries in Norway. Am J Obstet Gynecol. 2003;188(4):864-870.
20. Lumbiganon P, Laopaiboon M, Gulmezoglu AM, Souza JP, Taneepanichskul S, Ruyan P, et al. Method of delivery and pregnancy outcomes in Asia: the WHO global survey on maternal and perinatal health. Lancet; 2007-08:490-499.

21. Joshua PV, Betrán AP, Vindevoghel N, Souza JP, Torloni MR, Zhang J, et al. On behalf of the WHO Multi-Country Survey on Maternal and Newborn Health Research Network Use of the Robson classification to assess caesarean section trends in 21 countries: a secondary analysis of two WHO multi country surveys. Lancet; 2015;(3):260-270.

22. Caughey AB, Cahill AG. Safe prevention of the primary caesarean delivery. Obstetric Care Consensus. 2014;1:2-19.

Cite this article as: Ray A, Jose S. Analysis of caesarean-section rates according to Robson's ten group classification system and evaluating the indications within the groups. Int J Reprod Contracept Obstet Gynecol 2017;6:447-51. 